\title{
INDEFINITE PRONOUNS IN ASSAMESE
}

\author{
Pushpa Renu Bhattacharyya
}

The study describes the indefinite pronouns in Assamese with its complexity and unique features and put emphasis on the morphological, semantic and syntactic properties. The term pronoun is used in the sense of the nominal expression and the substitution in the nominal slot only.

Keywords: indefinite, morphology, syntax, semantics.

\section{Introduction}

The present study is a modest attempt at description of the extensively used form and function of indefinite pronouns in Assamese a New Indo-Aryan language recognized by the constitution of India as one of the official languages spoken in Assam, situated in the Bhrahmaputra valley of North East India spreading an area of 78,438.00 square kilometres. According to the census report of 2011, the population of Assam is 31,169,272 the total numbers of native speakers of Assamese being 16.8 million, while the language is spoken by over 20 million people belonging to heterogeneous speech communities living together. Assamese is agglutinative with a SOV word order and nominative-accusative case alignment system with subject-verb agreement.

\subsection{Pronouns in Assamese}

The term pronoun is used here as pro-nouns i.e., grammatical items that can replace nouns and noun phrases. It must be mentioned that in Assamese, epithets are used as post nominal modifiers of the head proper nouns and of the second and third person head pronouns. Pronouns in Assamese are free forms. They are pronounced fully and can function deictically as well as anaphorically. They can also be suffixed with various morphemes like classifiers, plural markers, case markers, particles, etc. On the basis of their morphological representations and semantic features the pronouns may be identified and classified into different subclasses accordingly. In terms of their discourse function and frequency of use all the subclasses of pronouns can be grouped into two distinct major subtypes - central pronouns and peripheral pronouns.

\subsubsection{Central pronouns}

The central pronouns consist of five subclasses:

i. Personal pronouns

ii. Demonstrative pronouns

iii. Relative pronouns

iv. Interrogative pronouns

v. Anaphoric pronouns

\subsubsection{Peripheral pronouns}

The peripheral pronouns consist of three subclasses:

i. Indefinite pronouns

ii. Universal pronouns

iii. Miscellaneous pronouns

The various forms of pronominals ${ }^{1}$ in Assamese exhibit idiosyncratic morphological patterns and syntactic behaviour inherent to those specific subclasses.

\section{Indefinite pronouns}

An indefinite pronoun is used to refer to unknown and unidentified persons or things exhibit human vs. non-human or inanimate distinctions inherently. The pronouns belonging to this group are in a logical sense quantitative that express various degrees of indefiniteness. The label indefiniteness is used to refer to a referent which is different from, but the same kind of entity as the one referred to before. The distribution of indefinite pronouns in syntax is highly complex with semantics and pragmatics features. They have both positive ${ }^{2}$ and negative variants. The positive indefinite pronouns are specific ${ }^{3}$ and nonspecific while the negative ones are non-specific only. Both the types of indefinite pronouns exhibit human vs. non-human or inanimate distinctions.

\subsection{Positive indefinite pronouns}

The positive non-specific indefinite pronouns encoding human and non-human or inanimate referents are simple and derived. The derived has compound, complex and reduplicated variants. Reduplication can be either full or partial or 
modified. Table 1 displays the subtypes of positive non-specific indefinite pronouns.

Table 1: Positive non-specific indefinite pronouns

\begin{tabular}{|c|c|}
\hline Forms & Human /Inanimate \\
\hline Simple & $\begin{array}{l}\text { keu / khenu / kunu 'someone' } \\
\text { kisu 'something } \\
{[-\mathrm{AN}] \text { ' }}\end{array}$ \\
\hline \multirow[t]{8}{*}{ Derived } & Compound (Human/Inanimate) \\
\hline & $\begin{array}{l}\text { zi-kunu 'anyone', } \\
\text { dui-eta /dui-sarita } \\
\text { 'a few [-AN]', } \\
\text { dui-sari / dui-ek } \\
\text { 'a few people' }\end{array}$ \\
\hline & Complex (Human/Inanimate) \\
\hline & $\begin{array}{l}\text { ḅale-man 'many', } \\
\text { kisu-man 'some', } \\
\text { zon-dijek } \\
\text { 'a few people' } \\
\text { elek-pelek } \\
\text { 'so and so (PL)' } \\
\text { egal-man } \\
\text { 'many [-AN]' }\end{array}$ \\
\hline & $\begin{array}{l}\text { Partially reduplicated } \\
\text { (Human/Animate) }\end{array}$ \\
\hline & zei-hei 'anyone' \\
\hline & $\begin{array}{l}\text { Fully reduplicated } \\
\text { (Human/Inanimate) }\end{array}$ \\
\hline & $\begin{array}{l}\text { kunu-kunu } \\
\text { 'someone (PL)' } \\
\text { kisu-kisu 'something(PL)[-AN]' }\end{array}$ \\
\hline
\end{tabular}

The types of simple indefinite pronouns have simple stems. The compounds are combinations of two free forms, e.g., two numerals dui-ek/duisari 'a few' or an interrogative pronoun and a relative pronoun as exemplified by zi-kunu 'anyone' respectively. A complex indefinite pronoun combines a bound form with a free form as in bale-man or egal-man 'many', where the bound suffix -man is used to imply approximation. A complex form may be a combination of two bound forms as in elek-pelek 'so and so'. In case of partial reduplication process two pronominal forms that belong to different subtypes combine together as in zei-hei 'anyone', zi-ti or za-ta 'whatever' where the second constituent is modified. The fully reduplicated pronouns take the same simple stem as the second element as kunu-kunu 'some'.

\subsection{Negative indefinite pronouns}

The negative indefinite pronouns express nonexistence. The negative non-specific indefinite pronouns having human and inanimate forms occur with negative verbs ${ }^{4}$ only. Table 2 represents negative indefinite pronouns in Assamese.

Table 2: Negative indefinite pronouns

\begin{tabular}{|l|l|}
\hline Forms & Human /Inanimate \\
\hline Simple & $\begin{array}{l}\text { kunu 'nobody } \\
\text { keu 'none' } \\
\text { eku 'nothing' }\end{array}$ \\
\hline Compound & $\begin{array}{l}\text { keu-kisu 'nobody' } \\
\text { eku-eta 'nothing' }\end{array}$ \\
\hline
\end{tabular}

As seen in Table 2, kunu 'someone' is used as a positive specific indefinite pronoun as a negative non-specific indefinite pronoun as well. It has another variant keu 'none'. The compound forms are combinations of a simple indefinite pronoun with another pronoun or a numeral. However, the indefinites that function as nominal modifiers are not pronouns, e.g., in kunu-zon manuh 'some persons', kunu-zon is a nominal modifier, but in kunu-zon 'someone' in isolation is an indefinite pronoun.

\section{Dependents of indefinite pronouns}

Adjectives may occur with indefinite pronouns in highly context bound utterances. The expression in (1) exemplifies an indefinite pronoun taking an adjective as a pre-head modifier.
(1) [notun] kiba
new something
'something new'.

The following exemplifies a compound indefinite pronoun as head taking an adjective as a premodifier. 
10 / Indefinite ...

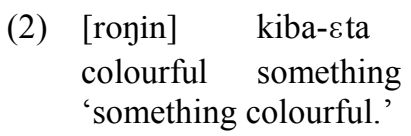

Indefinite pronouns occur with post modifiers also. In the following example an adjective functioning as a modifier occurs as a post-head dependent.

\section{(3) kunuba [ murkho ] some idiot 'some idiots.'}

The expression in (4) provides an evidence for the fact that an indefinite pronoun functions as head that takes an indefinite quantifier as its modifier.

\section{(4) kunuba [ kei-zoni -man] \\ IND QUAN-CL(SG:F)-APPROX 'a few girls.'}

The least frequent type of dependent of pronouns can be an appositive as exemplified by the following with an indefinite pronoun as the head that takes a proper noun as its dependent.

\section{(5) [kunuba ] [ benu borua] someone Benu Barua 'some Benu Barua.'}

The pronouns either personal or other subtypes take quantifiers (i.e., numeral plus classifier) as post-head modifiers.
(6) ЂihÕt [du-ta]
$3_{3}$ PL two-CL
'both of them.'
(7) kunuba [\&-zon]
IND one-CL
'some one.'

The above examples show that indefinite pronouns may take adjective (both pre and post head positions), nominal appositive and quantifier as pre modifiers.

\section{Morphophonemics and morphology}

The positive non-specific type of indefinite pronoun encodes human referents with direct stems- kunu, keu and $\mathrm{k}^{\mathrm{h}} \mathrm{enu}$ 'someone' and nonhuman referent kisu 'something [-AN]'only. These indefinites can occur with both positive and negative verbs. The first form kunu occurs as subject only, while all the others can function in different case marked positions. e.g.:

(8)

$\begin{array}{lll}\text { kunu-e } & \text { nas-is -e } & \text { kunu-e } \\ \text { IND-NOM } & \text { dance-IPFV-3 } & \text { IND-NOM }\end{array}$

ga-is-e

sing-IPFV-3

'Someone is dancing, someone is singing.'
(9) $\mathrm{k}^{\mathrm{h} e n U}-\mathrm{k} \quad \operatorname{dek}^{\mathrm{h}}-\mathrm{i} \quad$ besi
IND-ACC see-NF more
utsahi no-ho-ba
enthusiastic NEG-happen $-2_{2}$
'Don't be too enthusiastic by seeing others.'

Some derived composite forms of positive nonspecific indefinite pronouns are exemplified below.

(10) zikunu-e kam-tu

IND-NOM work-CL

kor-ibo par-e

do-NF can- 3

'Anyone can do the work.'
(11)

$\begin{array}{lll}\text { baleman-e } & \text { teu-r } & \text { kot }^{\mathrm{h}} \mathrm{a}-\mathrm{t} \\ \text { IND-NOM } & 3_{2} \text { SG-GEN } & \text { word-LOC } \\ \text { honmoti } & \text { zona-l-e } \\ \text { agreement } & \text { express-PST-3 } \\ \text { 'Many agreed with him / her.' }\end{array}$

One of the reduplicated positive non-specific indefinite pronouns shown in Table 2 exhibits a specific genitive construction, in which the initial constituent suffixed with the genitive case functions as the possessor and the final constituent as the head in a possessional construction as in elek-or pelek 'so and so (PL)' used to refer to some distant indefinite referents. It can be used in both subject and object positions with relevant cases.
(12) elek-or pelek-sloi iman
IND-GEN IND-DAT so
sinta no-kor-ib-a
worry NEG-do-FUT-2 2
'Don't bother much about so and so.'

The positive non-specific indefinite type has a unique partially and modified reduplicated variant with distinctions of humanness and animacy used to imply 'anyone' or 'anything.' The direct stems 
used for [+HUM] are zi-hi and zei-hei and its indirect stems are za-ta. It has a reduced variant without the initial phonemes /z-/ and /t-/ or / $/ \mathrm{h}-/$ as in genitive marked a-r ta-r and accusative marked $\mathrm{a}-\mathrm{k}$ ta-k. The [-AN] type has different variants that can be used to encode direct object only. Its indirect stems are zih-tih as illustrated in Table 3.

Table 3: Reduplicated indefinite pronouns

\begin{tabular}{|c|c|c|}
\hline Case & [+Human] & [-Animate] \\
\hline Nominative & $\begin{array}{l}\text { zi-ћi-(e), } \\
\text { zei-e - hei-e }\end{array}$ & zi-ti, za-ta, zi-ki \\
\hline Accusative & $\begin{array}{l}\text { za-k ta-k, a-k } \\
\text { ta-k }\end{array}$ & $\begin{array}{l}\text { zih-ok(e) tih-ok(e), } \\
\text { ziti, za ta }\end{array}$ \\
\hline Genitive & $\begin{array}{l}\text { za-r ta-r, } \\
\text { zeihei-r }\end{array}$ & $\begin{array}{l}\text { a-r ta-r, zih-or } \\
\text { tih-or }\end{array}$ \\
\hline Dative & $\begin{array}{l}\text { zeihei -loi, } \\
\text { zata-loi }\end{array}$ & ziti-loi, zata-loi \\
\hline
\end{tabular}

As seen from Table 3, in case of some reduplicated pronouns of this type, the same case is suffixed to both the constituents or both the constituents remain unmarked; while in others just one case is suffixed to the reduplicated constituent as a whole as exemplified.
(13) zei-e
hei-e
ene kam
IND-NOM IND-NOM like work
kor-ibo nu-(p)ar-e
do-NF NEG-can-3
'Anybody cannot do such a work.'
(14) zi -ti- $\varnothing \quad$ no-ko-ba
IND.ACC NEG- say- $2_{2}$
'Do not speak nonsense.'

(15) $\mathrm{a}-\mathrm{k}$

ta-k huḍ - i

IND-ACC IND-ACC

ask-NF

toma-r gor-tu ulia-l-u

2 SG-GEN house-CL find-PST-1

'I have managed to find your house by asking one and another.'

Before giving a description of the positive specific type, it is a necessary prerequisite to illustrate the negative type, as both are compositionally related.
The negative non-specific indefinite pronoun has both [+HUM] and [-HUM] variants as displayed in the Table 4 below.

Table 4: Negative non-specific indefinite pronouns

\begin{tabular}{|l|l|l|}
\hline Case & [+Human] & [-Human] \\
\hline Nominative & $\begin{array}{l}\text { kunu(e) /kuneu / } \\
\text { keu-e }\end{array}$ & eku(e) \\
\hline Accusative & kaku & eku \\
\hline Genitive & karu & - \\
\hline Dative & karu-loi & eku-loi \\
\hline
\end{tabular}

As presented in Table 4, the [+human] negative indefinite pronoun has three $U$-ending direct stems. They are- kunu-, kaku- and karu- 'nobody' / 'none'. The first is used to refer to subject, the second encodes direct object, while the third encodes possessor. As shown in the Table 4, the non-human indefinite pronoun eku 'nothing' shares the same direct stem for encoding all functions. Both the pronouns thus formed can be optionally be suffixed with the overt nominative marker depending on the transitivity of the verb. While there is no form for the genitive case for the non-human category, the accusative of both are unmarked for case, but the dative of both are overtly marked. The following exemplifies negative indefinite pronouns as subjects.

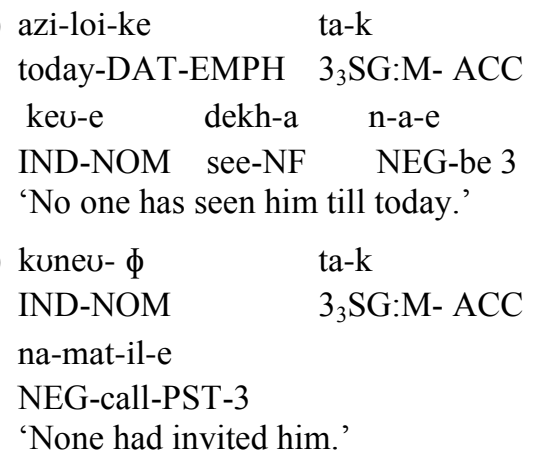

The examples in the following show its use as the object.

(18) kotha-tu kaku- $\phi$ no-ko-ba fact-CL IND. ACC NEG-say-FUT 2 'Don't divulge the fact to anyone.' 
(19) ta-k

$$
\text { eku- } \phi \quad \text { no-ko-ba }
$$

$3_{3}$ SG:M-ACC IND.ACC NEG-say-FUT2 2 'Don't tell him anything.'

The following is an example of compound negative non-specific indefinite pronoun.

(20) ta-r

keu-kisu n-a-e

$3_{3} \mathrm{SG}: \mathrm{M}-\mathrm{GEN}$

IND

NEG-be 3

'He has no one (i.e., kith and kin).'

Negative indefinite co-occurs only with negativised verbs as substantiated by the ungrammaticality of following sentences.
(21) * gor-ot kunu as-e
house-LOC IND be-3

$$
\begin{array}{cll}
* \text { kot }^{\mathrm{h}} \mathrm{a}-\mathrm{tu} & \text { kaku } & \text { ko-ba } \\
\text { fact }-\mathrm{CL} & \text { IND } & \text { say-FUT } 22_{2}
\end{array}
$$

Of the $[+\mathrm{HUM}]$ positive specific subtype with the specificity marker -ba the direct variant kunubatakes the nominative case and the oblique variant karuba takes all other case markers as in the following.

Table 5: Positive specific indefinite pronouns

\begin{tabular}{|l|l|l|}
\hline Stem & Case & Word form \\
\hline kunuba- & nominative & kunuba-(e) \\
karuba- & accusative & karuba-k \\
& genitive & karuba-r \\
& dative & karuba-loi \\
\hline
\end{tabular}

The following are examples of positive specific indefinite pronouns occurring in various syntactic positions.

(23) kunuba-e karuba-k

IND-NOM IND-ACC
mar-is-e

beat-IPFV-3

'Someone is beating some other.'

(24) kunuba- $\phi$ ah-is-e

IND-NOM come-IPFV-3

'Someone is coming.'

$\begin{array}{lll}\text { (25) kali } & \text { karuba-r } & \text { gor-ot } \\ \text { yesterday } & \text { IND-GEN } & \text { house-LOC }\end{array}$

$\begin{array}{ll}\text { suri } & \text { ho-is-e } \\ \text { theft } & \text { happen-IPFV-3 }\end{array}$

'There had been a theft yesterday at someone's home.'

The positive specific indefinite pronouns ki- and kih- used to refer to non-human and /or animate, non-animate referents are complex forms derived by the insertion of the specificity marker -(o)ba by the process of anaptyxis. It has two direct variants, one is kiba-, which does not take the overt nominative case and the other is kihoba'something', formed by insertion of the vowel $\rho$, followed by the specificity marker ba, which takes all case markers as shown by Table 6 .

Table 6: $[-\mathrm{HUM} / \pm \mathrm{AN}]$ Positive specific indefinite pronouns

\begin{tabular}{|c|l|l|}
\hline Direct stem & Case & Word form \\
\hline ki-/kih- & nominative & kiba / kihoba-e \\
\hline & accusative & $\begin{array}{l}\text { kiba / kihoba-k, } \\
\text { ziba }\end{array}$ \\
\hline & genitive & kihoba-r \\
\hline & dative & kihoba-loi \\
\hline
\end{tabular}

The sentences in (26) and (27) exemplify the use of positive specific indefinite pronouns.

(26) kiba- $\phi$ ko-ba neki

IND.ACC $\quad$ say- $2_{2} \quad$ QF

Do you want to say something?'

(27)
kihoba-e
mat-is-e
call-IPFV-3
'Something is producing a sound.'

These ba- ending indefinite pronouns need to be distinguished from the interrogative-indefinite pronouns with the dubitative particle -ba used to express the speaker's sense of doubt or anxiety interspersed with the question. Phonologically, the question word carries the rising intonation, while the dubitative particle is marked by a falling intonation. It has a limited number of contrastive forms for both human and non-human referents. Table 7 represents those pronouns.

Table 7: Interrogative-indefinite pronoun 


\begin{tabular}{|l|l|l|}
\hline Case & {$[+$ Human] } & [-Human] \\
\hline Nominative & kun-ba & ki-ba \\
\hline Accusative & kak-ba & kihok-ba \\
\hline Genitive & kar-ba & kihor-ba \\
\hline Dative & kaloi-ba & kiholoi-ba \\
\hline
\end{tabular}

The use of these pronouns in various case marked positions are shown below.

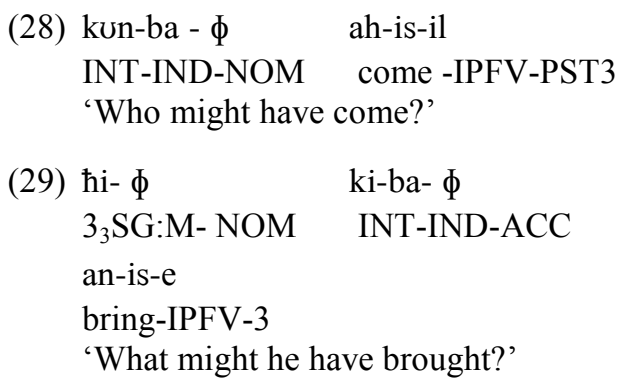

The bound form-(o)ba is used as a specific marker suffixed to question words or interrogative pronouns to derive the complex forms of positive specific indefinite pronouns like kunu-ba 'someone', kih-oba 'something', ki-ba 'something' and relative pronoun zi-ba 'whichever / whatever [-AN]', encoding human, non-human, animate and inanimate referents respectively. Some of them exhibit compound forms, e.g., kiba-eta 'something', kiba-kibi 'somethings' etc.

However, it has another ba- ending variant used as interrogative-indefinite pronoun, where a case marked interrogative pronoun is suffixed with -ba as a dubitative particle to express the speaker's sense of doubt or anxiety interspersed with the question. Phonologically, the question word carries the rising intonation, while the dubitative particle is marked by a falling intonation. It has a limited number of contrastive forms for both human (e.g., kun-ba, kak-ba, kar-ba) and nonhuman (e.g., ki-ba, kihək-ba, kihər-ba) referents.

However, the same form suffixed to the indefinite quantifier $k e i$ as $k e i-b a$ followed by classifiers may be used to imply 'quite a few' (Chowdhary 2012: 272) with reference to indefinite referents of various types of animacy, e.g., kei-ba-zon (human), kei-ba-ta (human / non-human / inanimate).

5 Marking of number

Number distinction has no grammatical bearing on the language. The morphological processes associated in the formation of plural forms of the various subclasses of pronouns are illustrated below.

Except few, most of the indefinite pronouns are inherently neutral in exhibiting number differentiations. The morphological processes associated in the formation of derived plural indefinite pronouns may be summed up as in the following:

i. Suffixation of plural markers

kunu'some (SG)'>kunu - bur / -bilak 'some (PL)'

\section{ii. Compounding}

zon-oik 'one person'> zon-diek 'more than one',

kiba-eta 'something [-HUM]'>kiba-kibi 'something (PL)[-AN]';

kunu'some (SG)'>kunu-kunu'some (PL)'.

elek-pelek 'so and so(PL)';

iii. Reduplication:

kiba'something (SG)'>kiba-kibi 'somethings', kunu'some (SG)'>kunu-kunu 'some', kunuba 'some (SG)'>kunuba kunuba 'some (PL)'

6 Marking of gender

In case of some indefinite pronouns gender is distinguished on the basis of whether the masculine classifier -zon, -tu or the feminine classifier -zoni is used as its final constituent, e.g., kun-tu 'which one (M)' > kun-zoni 'which one (F)'; kunu-zon 'someone (M)'> kunu-zoni 'someone (F)' respectively.

Gender in pronouns of Assamese is found to be only restrictively grammatical.

7 Semantic features of indefinite pronouns 
14 / Indefinite ...

The semantic feature of indefiniteness characterizes indefinite pronouns. They may encode positivity or negativity. The positive indefinite pronouns may again imply specificity or non-specificity. The semantic distinctions of animacy/inanimacy and humanness/nonhumanness are the additional salient features of indefinite pronouns. The final element $-U$, signalling indefiniteness is shared by most of the positive non-specific indefinite pronouns like kunu, keu, khenu, kisu 'someone' as well as negative non-specific indefinite pronouns karu, kaku 'none' and eku 'nothing' etc.

Specificity is associated with -(0)ba- ending indefinite pronouns as in kunuba-, karuba'someone', kiba 'something', kihoba 'something'.

The positive non-specific indefinite pronouns suffixed with classifiers indicate sex distinctions as in kunuzon 'someone (SG:M)', kunuzoni 'someone (SG:F).'

Reduplicated indefinite pronouns are used to mark plurality as in zeihei 'anyone', ziti/zata 'anything', zikunu 'any one', kunukunu 'some.'

The meaning differences can be seen in NPs with indefinite pronouns as the head with or without dependents. For example, kiba 'something' or kunuba 'someone' can have a specific sense when it occurs with a quantifier as it's dependent as in kiba eta 'something' or kunuba ezon 'someone.'

\section{Pragmatics of indefinite pronouns}

\subsection{Indirectness and politeness}

Indefinite pronouns are very deeply related with the concept of politeness. It has been argued that there is a correlation between indirectness and politeness. In general not to address another person too directly is considered to be a very general politeness strategy. For example, the subject position of the imperative sentence which is canonically characterized by an ellipse subject can be overtly filled up by an indefinite pronoun in place of the $2^{\text {nd }}$ person pronoun.
(30) kunuba - zu-a aru
IND -NOM go-IMP. $2_{2}$ and
sokidar - zon - ok mat-i
chowkidar-CL(SG:M)- ACC call-NF
an-a
bring-IMP. $2_{2}$
'Someone go and call the chowkidar.'

The opposite also holds true when in a specific context of discourse, the positive specific indefinite pronoun is used to make sarcastic remarks or utterances with a sense of mirth towards the addressee, e.g.,

(31)

kunuba-e ama $-\mathrm{k} \quad$ mot-a
IND-NOM $\quad$ 1PL-ACC call-NF
n-a-e
NEG-be-3
'Someone has not talked to us.'

This may be interpreted as 'Why are you not talking to me?'

The following is a conversation between a mother and her child expressing the small steps of politeness, where the mother indirectly accuses the child and the child tries to exonerate himself/ herself from the blame.

(32) Mother

kunuba-e kol $\mathrm{k}^{\mathrm{h}} \mathrm{a}-$
IND-NOM banana eat-PS
'Someone has eaten banana(
Child
moe - $\phi \quad \mathrm{k}^{\mathrm{h}} \mathrm{-a}$ nae
$1 \mathrm{SG}-\mathrm{NOM}$ eat-NF NEG
'I have not.'

The use of the positive specific indefinite pronoun renders a polite overtone to a question by turning it into an indirect one, as exemplified by the following pairs of utterances with the interrogative pronoun $\mathrm{ki}$ and the indefinite pronoun kiba.
(33) a. ki
ho-1
INT happen-PST.3
'What happened?' 
(33)

$\begin{array}{ll}\text { kiba ho-1 } & \text { neki } \\ \text { IND happen-PST.3 QF } & \text { QF } \\ \text { 'Has anything happened?' } & \end{array}$

The same is the case in the following pairs of utterances, where the use of the positive specific indefinite pronoun in sentence (b) encodes a polite enquiry about the stock of food in the house, in contrast to (a) with an interrogative pronoun which sounds more like a demand to know about it.

$$
\begin{aligned}
& \mathrm{k}^{\mathrm{h}} \mathrm{a}-\text { boloi } \mathrm{ki} \text { as-e } \\
& \text { eat-NF INT have-PRES.3 } \\
& \text { 'What is there to eat?' }
\end{aligned}
$$

(34) b. $k^{\mathrm{h}} \mathrm{a}-$ boloi kiba

$$
\begin{aligned}
& \text { eat-NF IND } \\
& \text { as-e } \\
& \text { have -PRES.3 neki } \\
& \text { 'Is there something to eat?' }
\end{aligned}
$$

\subsection{Generic Sense}

The positive non-specific indefinite pronouns are the best examples of generic interpretations, e.g.,

zikunu-e kam-tu kor-ibo par-e
IND-NOM work-CL do-NF can-3
'Anyone can do the work.'

\subsection{Special Sense}

The positive non-specific indefinite pronouns suffixed with classifiers indicate sex distinctions as in kunu-zon 'someone (SG:M)', kunu-zoni 'someone (SG:F)'.

$$
\begin{aligned}
& \text { kunu- zoni-e } \\
& \text { IND-CL(SG:F)-NOM } \\
& \text { kunu- zoni-e } \\
& \text { IND- CL(SG:F)-N }
\end{aligned}
$$

'Someone $(\mathrm{F})$ is dancing, someone $(\mathrm{F})$ is singing.'

\section{Conclusions}

The foregoing was an attempt to present the main features of indefinite pronouns in Assamese in terms of the forms and functions. The study shows that indefinite pronouns play an important role in the language.

\section{Acknowledgements}

Special thanks to Dr. Runima Chowdhary, former Associate Professor, Department of Linguistics, Guwahati University, Assam for her guidance.

\section{References}

Aldridge, Maurice V. 1982. English quantifiers: A study of quantifying expressions in linguistic science and modern English usage. Amersham: Avebury.

Bach, E. 1968. Nouns and noun phrases. In E. Bach, and Robert T. Harms (eds.), Universals in Linguistic Theory. New York: Holt, Rinehart, \&Winston, 91-124

Bakker, C.L. 1970. Double negatives. Linguistic Inquiry, 1:169-86.

Bhat, D. N. S. 1993. Indefiniteness and Indeterminacy. MS, Mysore, Central Institute of Indian Languages

Chowdhary, R.C. 2012. On Classifiers in Asamiya. In Hyslop G., S. Morey and M.W. Post (eds.) North East Indian Linguistics, Vol.4, Cambridge University Press India Pvt. Ltd.

Online References

Assamese Language, Web Retrieved from https://en.wikipedia.org/wiki/Assamese language on $7^{\text {th }}$ August, 2017

\footnotetext{
1 The term pronominal is used as replacer of nominal constructions.

${ }^{2}$ The term positive is used to describe presence while negative is used to describe absence of an indefinite quantity.

${ }^{3}$ The term specific refers to a particular instance of a class of referents and non-specific refers to the whole class of entities.

${ }^{4}$ Examples of negative indefinite pronouns occurring with negative verbs are shown in sub section 4 (examples 16-20).
} 